\title{
HYPOTHERMIC CARDIOPULMONARY BYPASS ALTERS OXYGEN/GLUCOSE UPTAKE IN THE PEDIATRIC BRAIN
}

Frank A. Pigula, MD

Ralph D. Siewers, MD

Edwin M. Nemoto, PhD
Objectives: Neurologic morbidity related to cardiac surgery has been recognized as a major morbidity. A variety of causes related to cardiopulmonary bypass, including microemboli, nonpulsatile flow, hemodilution, and inflammatory mediation, have been proposed. Because oxygen and glucose are the predominant metabolic substrates for the brain, we sought to examine the uptake of these substrates by the pediatric brain during hypothermic cardiopulmonary bypass.

Methods: Eleven children (median age 5 months, range 1 day-17 years) undergoing a variety of cardiac surgical procedures with the use of hypothermic cardiopulmonary bypass were studied. Cerebral arteriovenous differences for oxygen, glucose, and lactate were obtained before, during, and after bypass. On the basis of the predictable stoichiometric relationship for the oxidation of glucose, the relationship of substrate uptake was expressed as the oxygen/glucose index.

Oxygen/glucose index $(\%)=($ arteriovenous oxygen difference $[\mu \mathrm{mol} / \mathrm{mL}] /$ arteriovenous glucose difference $[\mu \mathrm{mol} / \mathrm{mL}] \times 6) \times 100$

Results: All children survived with no obvious neurologic sequelae. During cooling on cardiopulmonary bypass, the oxygen/glucose indexes fell significantly from prebypass values $\left(53 \% \pm 19 \%\right.$ at $28^{\circ} \mathrm{C}$ and $54 \% \pm 25 \%$ at $24^{\circ} \mathrm{C}$ vs $117 \% \pm 70 \% ; P<.05$, analysis of variance). This decline resulted from decreased oxygen uptake with stable glucose uptake $(P<.05)$. Although oxygen and glucose uptake both increased with rewarming, the net effect was only a slight increase in oxygen/glucose index $(62 \% \pm 16 \%)$. Postbypass oxygen/glucose index exceeded prebypass values $(149 \% \pm 83 \%)$.

Conclusions: Hypothermic cardiopulmonary bypass alters the relationship between oxygen and glucose uptake in the pediatric brain. The relationship of these findings to bypass-related neurologic morbidity remains to be explored. (J Thorac Cardiovasc Surg 2001;121:366-73)
From the Division of Cardiothoracic Surgery, Children's Hospital of Pittsburgh, Pittsburgh, Pa.

Read at the Eightieth Annual Meeting of The American Association for Thoracic Surgery, Toronto, Ontario, Canada, April 30-May 3, 2000.

Received for publication May 4, 2000; revisions requested Sept 5, 2000; revisions received Sept 21, 2000; accepted for publication Sept 29, 2000.

Address for reprints: Frank A. Pigula, MD, Cardiothoracic Surgery, 2 Main, Children's Hospital of Pittsburgh, Pittsburgh, PA 15213 (E-mail: pigulaf@heart.chp.edu).

Copyright (c) 2001 by The American Association for Thoracic Surgery

0022-5223/2001 $\$ 35.00+0 \quad \mathbf{1 2 / 6 / 1 1 2 2 0 7}$

doi: $10.1067 / \mathrm{mtc} .2001 .112207$
A dvances in myocardial protection and operative A technique have dramatically reduced mortality resulting from congenital heart disease. Because of these advances, attention is focusing on the neurologic sequelae of cardiac surgery. Ferry ${ }^{1}$ has documented that neuropsychiatric deficits may occur in up to $25 \%$ of children subjected to hypothermic cardiopulmonary bypass (CPB). Recently Visconti and associates ${ }^{2}$ reported that the intelligence quotient of children undergoing surgical closure of secundum atrial septal defects was significantly lower than that of children undergoing catheter closure. These concerns are particularly acute 
Volume 121, Number 2

Table I. Patient demographics, procedures, and CPB times for 11 children studied

\begin{tabular}{|c|c|c|c|c|}
\hline Patient (sex, age) & Procedure & Body weight $(\mathrm{kg})$ & $C P B$ time (min) & $C A T$ (min) \\
\hline 1 (M, 4 mo) & VSD & 3.6 & 98 & \\
\hline $2(\mathrm{M}, 10 \mathrm{mo})$ & VSD, PA plasty & 5.7 & 131 & \\
\hline $3(\mathrm{M}, 5 \mathrm{mo})$ & VSD, ASD & 4.9 & 87 & \\
\hline $4(\mathrm{~F}, 3 \mathrm{y})$ & AVSD & 12.6 & 71 & \\
\hline $5(\mathrm{M}, 4 \mathrm{~d})$ & Arterial switch & 3.7 & 174 & 11 \\
\hline $6(\mathrm{M}, 1 \mathrm{~d})$ & TAPVR & 3.4 & 104 & 38 \\
\hline 7 (F, 17 y) & Ross & 90 & 214 & \\
\hline $8(\mathrm{M}, 5 \mathrm{mo})$ & TOF & 9.7 & 103 & \\
\hline $9(\mathrm{~F}, 13 \mathrm{mo})$ & AVSD & 7 & 87 & \\
\hline $10(\mathrm{M}, 3 \mathrm{mo})$ & TOF & 6.5 & 118 & \\
\hline $11(\mathrm{M}, 11 \mathrm{mo})$ & BDG & 8 & 100 & \\
\hline
\end{tabular}

$C P B$, Cardiopulmonary bypass; $C A T$, circulatory arrest time; $V S D$, ventricular septal defect; $P A$, pulmonary artery; $A S D$, atrial septal defect; $A V S D$, atrioventricular septal defect; TAPVR, total anomalous pulmonary venous return; TOF, tetralogy of Fallot; $B D G$, bidirectional Glenn shunt.

in the pediatric population, in which the effects of a neurologic injury may accrue over decades.

A variety of causes for CPB-related neurologic injury have been proposed. These include microemboli, nonpulsatile flow, hemodilution, $\mathrm{pH}$ management, pump flow, and temperature management. ${ }^{3-5}$ Although many groups have documented the effects of hypothermic $\mathrm{CPB}$ on the cerebral metabolic rates of oxygen $\left(\mathrm{CMR}_{\mathrm{O} 2}\right)$ and glucose $\left(\mathrm{CMR}_{\mathrm{gluc}}\right)$, the relationship between these two substrates (oxygen and glucose) remains largely unexamined.

\section{Methods}

In the well-fed state, cerebral metabolism predominately depends on two substrates for energy production: oxygen and glucose. ${ }^{6}$ The oxidation of glucose is described by the equation:

$$
\text { Glucose }+6 \mathrm{O}_{2} \rightarrow 6 \mathrm{CO}_{2}+6 \mathrm{H} 2 \mathrm{O}
$$

The stoichiometry of this relationship is such that if all glucose is oxidized, the ratio of arterial-venous difference of oxygen and glucose $\left(\mathrm{A}-\mathrm{VD}_{\mathrm{O} 2} / \mathrm{A}-\mathrm{VD}_{\text {gluc }}\right)$ must be 6 . Thus, if all the glucose extracted is not oxidized, the ratio will be less than 6 . If carbon is provided by alternative substrates (ie, ketone bodies), the ratio will be greater than 6 . This well-defined relationship has been codified by Cohen, ${ }^{7}$ Seisjo, ${ }^{8}$ and their associates and is represented by the oxygen/glucose index (OGI).

$$
\begin{gathered}
\text { OGI }(\%)=\left(\mathrm{A}-\mathrm{V}_{\mathrm{O} 2}[\mu \mathrm{mol} / \mathrm{mL}] / \mathrm{A}-\mathrm{V}_{\text {gluc }}\right. \\
[\mu \mathrm{mol} / \mathrm{mL}] \times 6) \times 100
\end{gathered}
$$

Using the OGI, we studied the effects of hypothermic CPB on oxygen and glucose uptake by the brain in 11 pediatric patients. Informed consent was obtained from all patients or their parents. Eleven pediatric patients aged 1 day to 17 years (median age 5 months) were studied. Anesthetic management consisted of isoflurane and high-dose opiates. After intubation, the arterial line and the esophageal and rectal temperature probes were placed.
After sternotomy but before CPB, a jugular bulb catheter was inserted at the confluence of the innominate vein and superior vena cava. The catheter was premeasured and threaded to the level of the ear. Positioning of the catheter at least at the angle of the mandible was confirmed with a handheld ultrasound probe (Site Rite; Dymax Corp, Pittsburgh, $\mathrm{Pa})$. Jugular venous samples $(1 \mathrm{~mL})$ were slowly withdrawn to avoid retrograde contamination with extracranial blood. A simultaneous arterial sample was obtained. All blood samples were obtained in duplicate and analyzed for $\mathrm{pH}, \mathrm{PO}_{2}, \mathrm{PCO}_{2}$, lactate, glucose, hemoglobin, hemoglobin saturation, and oxygen content with the use of an ABL 700 Radiometer blood gas machine (Radiometer, Copenhagen, Denmark). Results of the duplicate samples were averaged and used to calculate the OGI, as described.

Paired, simultaneous blood samples were obtained (1) before $\mathrm{CPB},(2)$ during $\mathrm{CPB}$ halfway to the target temperature, (3) at the temperature nadir, (4) during rewarming halfway to $37^{\circ} \mathrm{C}$, (5) during $\mathrm{CPB}$ after rewarming, and (6) 5 minutes after $\mathrm{CPB}$. The samples were analyzed immediately after withdrawal. Standard CPB management techniques were used. Hemoglobin concentration was maintained above $6.0 \mathrm{~g} / \mathrm{dL}$. Pump flow rates were maintained at 1.5 to $2.5 \mathrm{~L}$. $\mathrm{min}^{-1} \cdot \mathrm{m}^{-2}$ but varied with temperature and procedure. Blood gas management was by the alpha-stat technique.

$\mathrm{A}-\mathrm{VD}_{\mathrm{O} 2}$ was calculated as the sum of the combined hemoglobin and dissolved oxygen content. Dissolved plasma oxygen content was calculated with the use of the temperaturecorrected Bunsen solubility coefficient with corrections for water vapor and barometric pressure. ${ }^{9}$

Statistical analysis. All data are presented as mean \pm standard deviation. Statistical analyses were performed with the Prophet version 6.0 graphic and statistical package (MarketMiner, Inc, Charlottesville, Va). Statistical procedures used included 1-way and 2-way analysis of variance with post hoc analysis using the Welch-Satterthwaite approximation, the Friedman test, and the Tukey procedure. Regression analysis was used to evaluate correlations between OGI and temperature. 
Table II. Cerebral arterial-venous (A-V) variables for oxygen, glucose, and lactate and the OGI before, during, and after hypothermic $C P B$ in 11 pediatric patients

\begin{tabular}{|c|c|c|c|c|c|c|}
\hline Variable & Pre-CPB & $\begin{array}{c}\text { Cool on } \\
\text { CPB } 1\end{array}$ & $\begin{array}{l}\text { Cool on } \\
\text { CPB } 2\end{array}$ & $\begin{array}{l}\text { Rewarm } \\
\text { on } C P B\end{array}$ & $\begin{array}{l}\text { At temp } \\
\text { on } C P B\end{array}$ & $\begin{array}{l}O f f \\
C P B\end{array}$ \\
\hline \multicolumn{7}{|l|}{ Temperature $\left({ }^{\circ} \mathrm{C}\right)$} \\
\hline No. & 10 & 11 & 11 & 9 & 11 & 11 \\
\hline Average & $35.2 *$ & 27.4 & 24.3 & 26.7 & $34.3^{*}$ & $36.3^{*}$ \\
\hline Standard deviation & 1.5 & 3.3 & 3.8 & 5.7 & 2.3 & 0.8 \\
\hline \multicolumn{7}{|l|}{ OGI $(\%)$} \\
\hline No. & 9.0 & 9.0 & 9.0 & 9.0 & 9.0 & 9.0 \\
\hline Average & $117.0^{*}$ & 52.5 & 54.0 & 60.1 & 61.6 & $146.4^{*}$ \\
\hline Standard deviation & 70.3 & 19.1 & 25.2 & 19.3 & 16.2 & 82.7 \\
\hline \multicolumn{7}{|l|}{ A-V oxygen $(\mu \mathrm{mol} / \mathrm{L})$} \\
\hline No. & 10.00 & 11.00 & 11.00 & 10.00 & 11.00 & 11.00 \\
\hline Average & 2.50 & 1.14 & 1.44 & 2.24 & 2.80 & 2.60 \\
\hline Standard deviation & 0.86 & 0.51 & 0.60 & 0.97 & 0.87 & 0.81 \\
\hline \multicolumn{7}{|c|}{$\mathrm{A}-\mathrm{V}$ glucose $(\mu \mathrm{mol} / \mathrm{mL})$} \\
\hline No. & 10.00 & 11.00 & 11.00 & 10.00 & 11.00 & 11.00 \\
\hline Average & 0.39 & 0.41 & 0.60 & 0.59 & 0.76 & 0.37 \\
\hline Standard deviation & 0.19 & 0.37 & 0.81 & 0.39 & 0.40 & 0.20 \\
\hline \multicolumn{7}{|l|}{ A-V lactate } \\
\hline No. & 10 & 11.0 & 11.0 & 11.0 & 7.0 & 11.0 \\
\hline Average & 1.27 & 2.48 & 2.79 & $3.4 \dagger$ & $3.7 \dagger$ & $3.4 *$ \\
\hline Standard deviation & 0.23 & 1.67 & 1.93 & 2.33 & 3.27 & 3.06 \\
\hline
\end{tabular}

Temperature: $* \mathrm{P}<.01$ compared with $O n C P B 1$, On CPB 2, and Rewarm 1 .

OGI: $* P<.01$ compared with $O n C P B$.

A-V oxygen: $* P<.01$ compared with $O n C P B 1$ and Rewarm $1 ; \dagger P<.01$ compared with $C P B 1$ and $C P B 2$.

A-V lactate: $* P<.05$ compared with Pre-CPB; $† P=.01$ compared with Pre-CPB.

\section{Results}

There were no deaths or observed neurologic complications. The procedures, ages, and weights are shown in Table I. With the exception of 2 patients, all were maintained on continuous CPB support. Target temperatures varied with the procedure and were subject to the surgeon's discretion. Average duration of CPB was $117 \pm 42$ minutes.

Prebypass mean cerebral OGI was $117 \% \pm 70 \%$ (Table II). OGI fell to $53 \% \pm 19 \%$ with the initiation of $\mathrm{CPB}$ and $54 \% \pm 25.2 \%$ and at lowest average temperature $(P=.01$, Fig 1$)$. With rewarming halfway to $37^{\circ} \mathrm{C}$, OGI increased to $60 \% \pm 19 \%$. After rewarming but before separation from CPB, the OGI was $61 \% \pm 16 \%$. Off $\mathrm{CPB}$ at $36^{\circ} \mathrm{C}$, OGI increased to $146 \% \pm 83 \%$. The reduction of OGI during cooling was apparently attributable to a reduction in $\mathrm{A}-\mathrm{VD}_{\mathrm{O} 2}$ without a parallel reduction in $\mathrm{A}-\mathrm{VD}_{\text {gluc }}$ (Fig 2). However, during rewarming $\mathrm{A}-\mathrm{VD}_{\mathrm{O} 2}$ increased, with a smaller increase in A$\mathrm{VD}_{\text {gluc }}$. The net effect was a slight increase in the OGI to $61 \%$. After $\mathrm{CPB}$, jugular venous lactate increased significantly compared with pre-CPB levels (Fig 2).

Although arterial glucose concentrations increased significantly during the $\mathrm{CPB}$ period, they peaked at an average level of $160 \mathrm{mg} / \mathrm{dL}$ and necessitated no treat- ment (Fig 3). There was no correlation between serum glucose levels and OGI (Fig 4). However, there was a significant and direct correlation between OGI and temperature (Fig 5). As expected, calculation of the A$\mathrm{V}$ dissolved oxygen as a percentage of the total oxygen uptake revealed significant increases in dissolved oxygen uptake by the brain during cooling (Table III).

\section{Discussion}

Oxygen and glucose are recognized as the most important substrates for energy metabolism in the brain. ${ }^{6,10}$ In 1964, Cohen and associates ${ }^{7}$ codified the relationship between oxygen and glucose uptake by the brain into the OGI. This index is useful for illustrating the balance of oxygen and glucose uptake by the brain on a molar basis, and it is independent of brain blood flow.

We have used the OGI to study the relationship on oxygen and glucose uptake by the pediatric brain during hypothermic CPB. During cooling, the OGI declined from before CPB to CPB nadir $(117 \% \pm 70 \%$ vs $53 \% \pm 19 \% ; P<.05)$. This decline in OGI occurred as the result of a significant decrease in oxygen uptake in the face of stable glucose uptake. This decline in cerebral oxygen uptake during cooling has been well described. ${ }^{11}$ However, declining oxygen uptake in the 


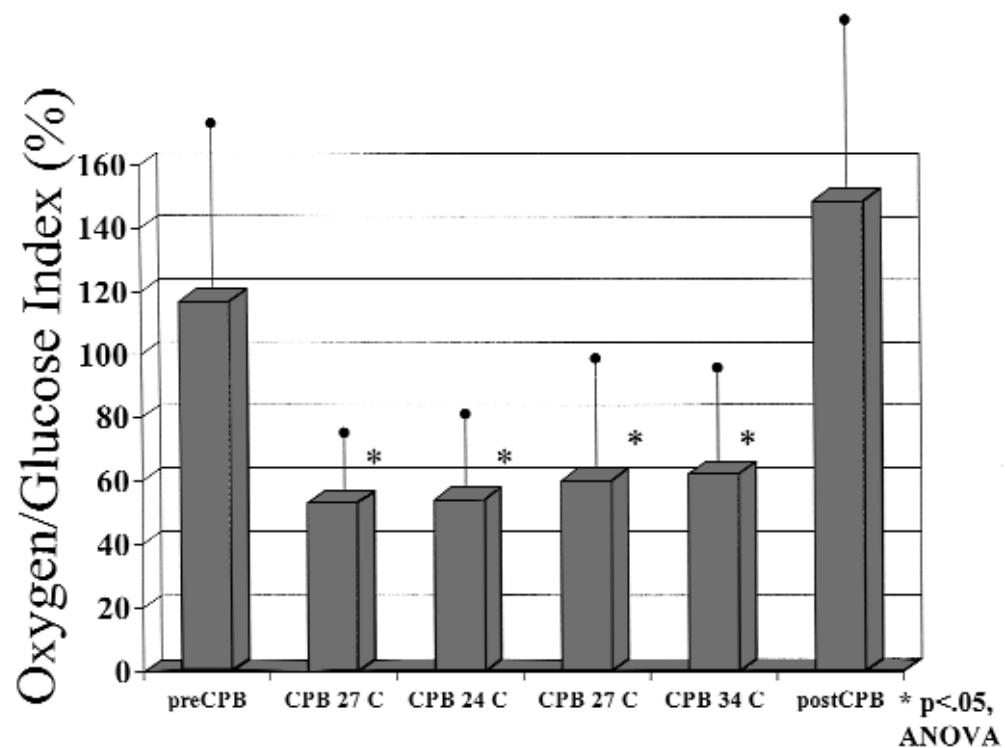

Fig 1. OGI decreases significantly during both the cooling and rewarming phase of hypothermic CPB in children $(P<.05$, analysis of variance $[A N O V A])$.

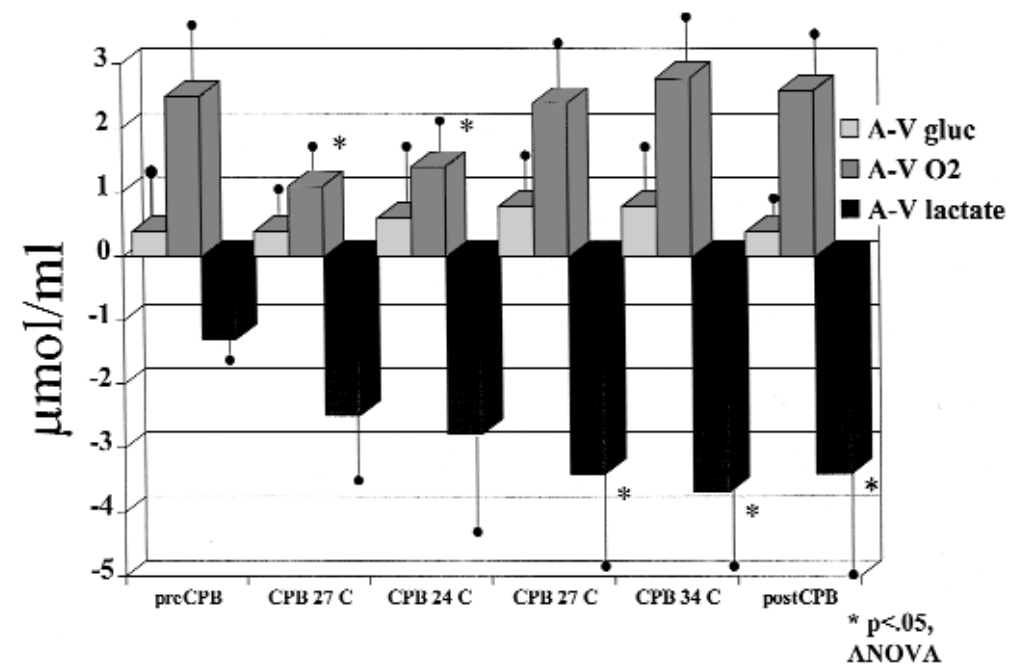

Fig 2. Cerebral arterial-venous differences $(A-V)$ of oxygen, glucose, and lactate as measured via arterial and jugular venous catheters. During cooling, there is a significant decline in cerebral oxygen uptake despite stable cerebral glucose uptake. Significant increases in cerebral lactate efflux $(A-V)$ occur with rewarming. ANOVA, Analysis of variance.

face of continued glucose uptake reduces the OGI. The lack of a parallel increase in lactate efflux from the brain during cooling suggests that it is not undergoing anaerobic metabolism. The net result of stable cerebral glucose uptake, in the face of declining cerebral oxygen uptake, would be relative cerebral hyperglycemia. Although elevations in plasma glucose during CPB are known to occur, the changes in OGI do not appear to be related to arterial glucose concentrations for two reasons: (1) at $27^{\circ} \mathrm{C}$ cooling the arterial glucose concentration is unchanged from pre-CPB levels and the OGI has already decreased to $54 \%$ at this point and (2) when OGI is plotted as a function of arterial glucose, no correlation can be identified. 


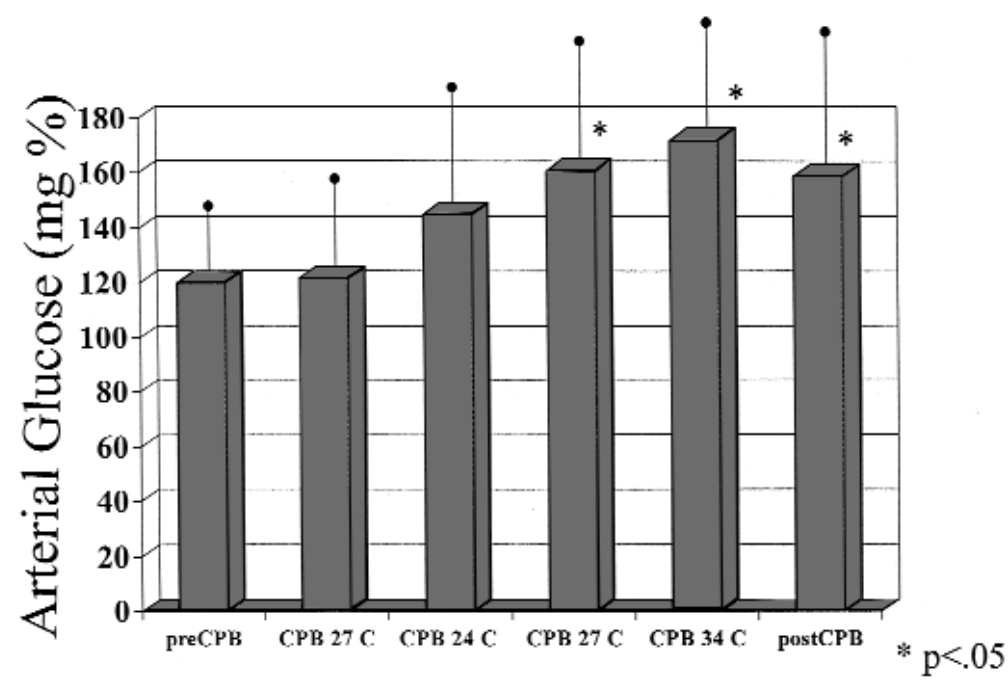

Fig 3. Although arterial glucose increased throughout the CPB period, glucose levels peaked at $160 \mathrm{mg} / \mathrm{dL}$, and no patient required treatment.

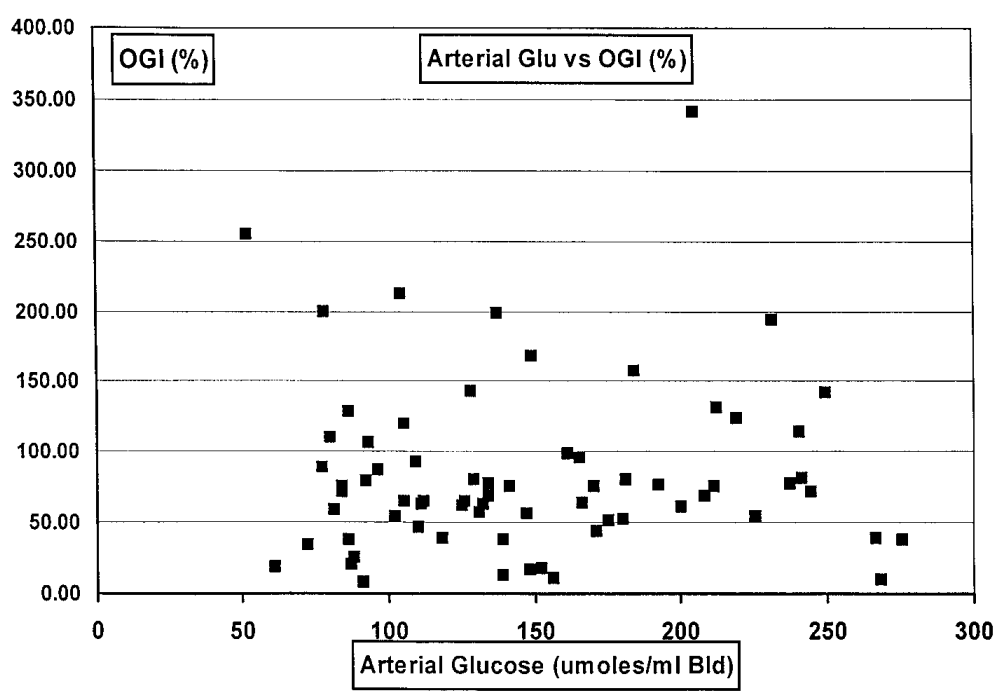

Fig 4. Scatterplot of arterial glucose $(G l u)$ concentrations versus OGI revealed no correlation between the two variables. Bld, Blood.

These findings, although preliminary, are noteworthy because both experimental and clinical evidence suggest that hyperglycemia during $\mathrm{CPB}$ is detrimental to the brain. ${ }^{12-14}$

With rewarming, A-V oxygen content increases, a widely described phenomenon ${ }^{15}$. A-V glucose also increases, albeit to a lesser extent. The net effect on OGI is minor however, because it increases only slightly to $61 \%$. This observation, along with the finding that cerebral lactate efflux increases significantly with rewarming, suggests that the brain is experiencing an anaerobic transient. Sapire and coworkers ${ }^{15}$ also reported increased lactate efflux from the brain in adults during rewarming and reached the same conclusion.

Increasing oxygen uptake, with increasing lactate efflux, amounts to a metabolic paradox. It is presumed that aerobic oxidative metabolism will predominate as oxygen uptake and $\mathrm{CMRO}_{2}$ increase with rewarming. However, as has been suggested by Anderson and col- 


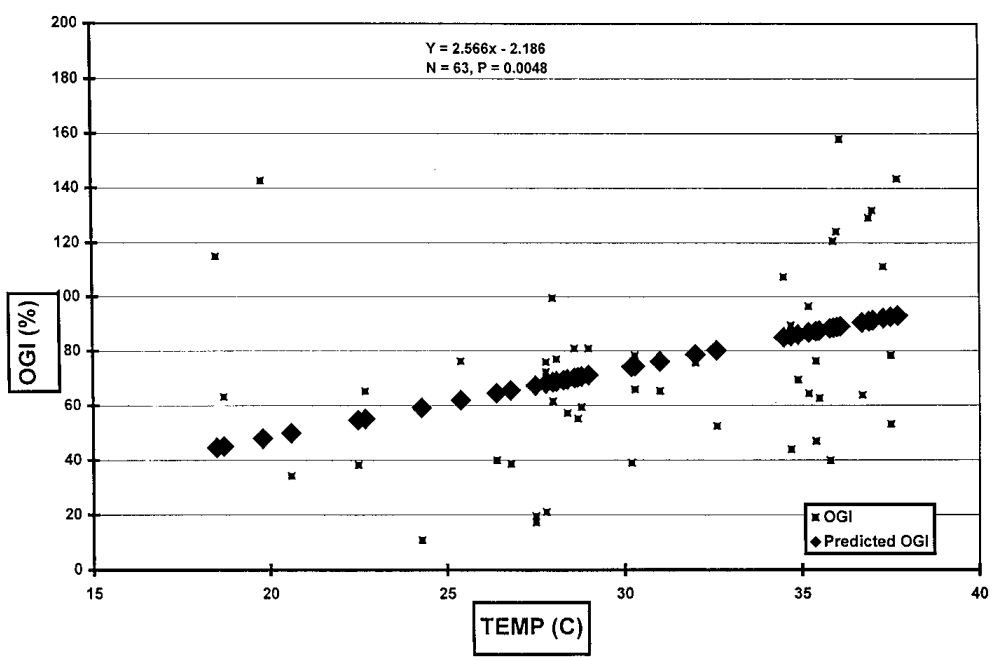

Fig 5. Linear regression analysis of OGI as a function of temperature established a significant correlation. OGI declined with decreasing temperatures $(P=.005)$.

Table III. $A-V$ dissolved oxygen as percent of total $A-V$ oxygen in 11 patients during $C P B$

\begin{tabular}{lcccccc}
\hline & Pre-CPB & Cool CPB 1 & Cool CPB 2 & Rewarm CPB & At temp CPB & Off CPB \\
\hline Average & 8.00 & $32.75^{*}$ & $17.50 \dagger$ & 15.36 & 6.51 & 12.47 \\
Standard deviation & 12.54 & 24.11 & 9.40 & 11.25 & 3.48 & 9.77 \\
\hline
\end{tabular}

$* \mathrm{P}=.01$ compared with Pre- $C P B$ and At temp.

$\dagger \mathrm{P}=.05$ compared with Pre-CPB.

leagues, ${ }^{14}$ a local abundance of glucose may drive its metabolism by any means available, including via anaerobic pathways, resulting in increased jugular venous lactate. After CPB, OGI increased significantly to $149 \%$, suggesting either oxidation of alternative substrates (ie, ketone bodies) or payback of an oxygen debt incurred during the CPB period. With elevations in brain lactate efflux, the latter seems more likely, although circulating ketones were not measured.

$\mathrm{CMR}_{\mathrm{O} 2}$ and $\mathrm{CMR}_{\text {gluc }}$ during $\mathrm{CPB}$ have been the subject of intensive study. Post hoc analysis of three experimental reports and one clinical report describing the $\mathrm{CMR}_{\mathrm{O} 2}$ and $\mathrm{CMR}_{\text {gluc }}$ have shown similar reductions in the OGI during CPB. In puppies, Mezrow and associates ${ }^{16}$ calculated that OGI fell from an average of $70 \%$ before $\mathrm{CPB}$ to an average of $59 \%$ on CPB at $18^{\circ} \mathrm{C}$. In piglets subjected to normothermic $\mathrm{CPB}$, analysis of $\mathrm{CMR}_{\mathrm{O} 2}$ and $\mathrm{CMR}_{\text {gluc }}$ published by Nomura and coworkers, ${ }^{17}$ showed a calculated OGI of $27 \%$ to $40 \%$. Likewise, calculations for OGI based on $\mathrm{CMR}_{\mathrm{O} 2}$ and $\mathrm{CMR}_{\text {gluc }}$ obtained in a similar model by Hiramatsu and colleagues ${ }^{18}$ ranged between $46 \%$ and $55 \%$. Although analyses of this type are prone to methodologic error as a result of interspecies variation, data variability, and estimations from mean values, they do suggest that the relationship of oxygen and glucose uptake by the brain is altered during CPB. In the clinical setting, Bergsneider and associates ${ }^{19}$ studied the $\mathrm{CMR}_{\mathrm{O} 2}$ and $\mathrm{CMR}_{\text {gluc }}$ in adults with severe traumatic brain injury. They found that these patients uniformly had cerebral hyperglycolysis, defined as "an abnormal cellular state of increased glucose metabolism relative to the rate of oxygen utilization" and concluded that this represented a nonphysiologic uncoupling between glycolytic and oxidative metabolism. The average OGI of these patients, calculated from the measured $\mathrm{CMR}_{\mathrm{O} 2}$ and $\mathrm{CMR}_{\text {gluc }}$, was $25 \% \pm 5 \%$ (range $17 \%-29 \%$ ).

Limitations of the study should be recognized. Although the technique of cerebral A-V sampling with a retrograde jugular catheter is commonly used in both clinical and experimental settings, it may be susceptible to methodologic errors. Contamination of the jugu- 
lar vein samples by extracerebral sources of venous blood would tend to reduce the apparent cerebral A-V oxygen differences, resulting in a facetious reduction of the OGI. Because of this, efforts to minimize these errors were made. Premeasurement of the catheter to the base of the skull, direct insertion of the catheter at operation, and ultrasound imaging to confirm catheter position were performed. Despite these concerns, however, our baseline values for $\mathrm{A}-\mathrm{V}$ oxygen and $\mathrm{A}-\mathrm{V}$ glucose are quite consistent with values obtained from 70 anesthetized children by Settergren, Lindblad, and Persson. ${ }^{20}$ Their measured cerebral A- $\mathrm{V}_{\mathrm{O} 2}(2.17$ $\mu \mathrm{mol} / \mathrm{mL}$, SE 0.9$)$ and $\mathrm{A}-\mathrm{V}_{\text {gluc }}(0.36 \mu \mathrm{mol} / \mathrm{mL}, \mathrm{SE} 0.3)$ are similar to our values $\left(\mathrm{A}-\mathrm{V}_{\mathrm{O} 2} 2.5 \mu \mathrm{mol} / \mathrm{mL}, \mathrm{SD} 0.9\right.$; A- $\mathrm{V}_{\text {gluc }} 0.4 \mu \mathrm{mol} / \mathrm{mL}, \mathrm{SD} 0.9$ ).

Also, significant variability exists within our data. This may reflect the heterogeneous nature of the sample group, including 2 patients subjected to circulatory arrest, with a wide range of ages ( 1 day-17 years) and cardiac diseases. The impact of these variables on cerebral oxygen and glucose uptake by the brain during CPB are unknown, and because of the relatively small sample size, the possibility for a type II statistical error cannot be ignored.

The relationship between altered oxygen and glucose uptake by the brain during CPB to neurologic outcome is uncertain, and we did not perform neuropsychiatric or anatomic examinations in our patients. Furthermore, no attempts were made to correlate OGI to other important but dynamic variables encountered during CPB, such as cerebral vascular tone or cerebral blood flow. Methodologic considerations make an animal model most appropriate for these investigations.

In summary, this preliminary study reveals potentially important alterations in the relationship between oxygen and glucose uptake by the pediatric brain during hypothermic $\mathrm{CPB}$. We have observed a relationship between temperature, OGI, and jugular venous lactate that suggests uncoupling of substrate uptake during cooling, with evidence of cerebral anaerobic metabolism during rewarming. The relationship between these findings, CPB-related neuropsychiatric injury, and other forms of brain injury remain unknown. Reproduction of these findings, ideally with anatomic and developmental correlates, is required.

\section{REFERENCES}

1. Ferry PC. Neurologic sequelae of open heart surgery in children. Am J Dis Child 1990;144:369-73.

2. Visconti KJ, Bichell DP, Jonas RA, Newberger JW, Bellinger DC. Developmental outcome after surgical versus interventional closure of secundum atrial septal defect in children. Circulation 1999;100(Suppl):II-145-50.
3. Moody DM, Brown CR, Challa VR, et al. Brain microemboli associated with cardiopulmonary bypass: a histologic and magnetic resonance imaging study. Ann Thorac Surg 1995;59:13047.

4. Mutch WAC, Lefevre GR, Thiessen DB, Girling LG, Warrian RK. Computer controlled cardiopulmonary bypass increases jugular venous oxygen saturation during rewarming. Ann Thorac Surg 1998;65:59-65.

5. Kurth CD, Steven JM, Nicolson SC, Jacobs ML. Cerebral oxygenation during cardiopulmonary bypass in children. J Thorac Cardiovasc Surg 1997;113:71-9.

6. Clarke DD, Sokoloff L. Circulation and energy metabolism of the brain. In: Siegel GJ, Agranoff BW, Albers RW, Molinoff PB, editors. Basic neurochemistry. 5th ed. New York: Raven Press; 1994. p. 645-80.

7. Cohen PJ, Wollman H, Alexander SC, Chase PE, Behar MG. Cerebral carbohydrate metabolism in man during halothane anesthesia. Anesthesiology 1964;25:185-91.

8. Siesjo BK. Utilization of substrates by brain tissues. In: Brain energy metabolism. New York: John Wiley; 1978. p. 101-25.

9. Christoforides C, Laasberg LH, Hedley-Whyte J. Effect of temperature on solubility of $\mathrm{O}_{2}$ in human plasma. J Appl Physiol 1969;26:56-60.

10. Sokoloff L. Circulation and energy metabolism of the brain. In: Seigel GJ, Agranoff BW, Albers RW, Molinoff RB, editors. Basic neurochemistry, 3rd ed. Boston: Little, Brown; 1981. p. 471-95.

11. Kern FH, Ungerleider RM, Schulman SR, et al. Comparing two strategies of cardiopulmonary bypass cooling on jugular venous oxygen saturation in neonates and infants. Ann Thorac Surg 1995;60:1198-202.

12. Stewart DJ, Da Silva CA, Flegel T. Elevated glucose levels may increase the danger of neurologic deficit following profound hypothermic cardiac arrest. Anesthesiology 1988;68:653-5.

13. Ekroth R, Thompson RJ, Lincoln C, et al. Elective deep hypothermia with total circulatory arrest: changes in plasma creatine kinase $\mathrm{BB}$, blood glucose, and clinical variables. J Thorac Cardiovasc Surg 1989;97:30-5.

14. Anderson RV, Siegman MG, Balaban RS, Ceckler TL, Swain JA. Hyperglycemia increases cerebral intracellular acidosis during circulatory arrest. Ann Thorac Surg 1992;54:1126-30.

15. Sapire KJ, Gopinath SP, Farhat G, et al. Cerebral oxygenation during warming after cardiopulmonary bypass. Crit Care Med 1997;25:1655-62.

16. Mezrow CK, Gandsas A, Sadeghi AM, et al. Metabolic correlates of neurologic and behavioral injury after prolonged hypothermic circulatory arrest. J Thorac Cardiovasc Surg 195;109:959-75.

17. Nomura F, Forbess JM, Jonas RA, et al. Influence of age on cerebral recovery after deep hypothermia circulatory arrest in piglets. Ann Thorac Surg 1996;62:115-22.

18. Hiramatsu T, Miura T, Forbess JM, et al. PH strategies and cerebral energetics before and after circulatory arrest. J Thorac and Cardiovasc Surg 1995;109:948-58.

19. Bergsneider M, Hovda DA, Shalmon E, et al. Cerebral hyperglycolysis following severe traumatic brain injury in humans: a positron emission tomography study. J Neurosurg 1997; 86:241-51.

20. Settergren G, Lindblad BS, Persson B. Cerebral blood flow and exchange of oxygen, glucose, ketone bodies, lactate, pyruvate, and amino acids in anesthetized children. Acta Paediatr Scand 1980;69:457-65. 


\section{Discussion}

Dr Richard A. Jonas (Boston, Mass). Your report highlights the fact that we continue to undertake cardiac surgery using $\mathrm{CPB}$ with extreme manipulations of flow, hematocrit value, and $\mathrm{pH}$ with no direct monitoring as to the adequacy of oxygen delivery. Clearly this is most important for the organ that is most sensitive to continuing oxygen delivery-the brain. Because of the absence of an adequate method for monitoring brain oxygenation, Dr Pigula has used an invasive method for assessing cerebral metabolism during CPB.

The finding that the decrease in oxygen delivery is greater than the decrease in glucose delivery is entirely consistent with many studies that we have published from Children's Hospital, Boston, over the past several years. These studies, primarily conducted in the laboratory, have used methods such as magnetic resonance spectroscopy and near-infrared spectroscopy to assess cerebral oxygen delivery. The studies have led us to the conclusion that a combination of an alkaline $\mathrm{pH}$ strategy, as well as hemodilution to a hematocrit of $20 \%$ or less and reduced flow, such as you used in this study, down to an index of $1.5 \mathrm{~L} \cdot \mathrm{min}^{-1} \cdot \mathrm{m}^{-2}$, are additive in their effect of limiting oxygen delivery.

I do not understand why you saw some delay in lactate production. Roger Mee referred to production of acid during CPB in yesterday's session. However, in our own studies we have generally seen a rise in lactate even during the cooling phase of CPB if we use a CPB strategy that has an inappropriate combination of alkalosis, hemodilution, and reduced flow. During rewarming, however, you have seen an ongoing increase in lactate production. Perhaps the rate of anaerobic metabolism was sufficiently depressed in your patients during hypothermia that you were unable to measure increasing lactate level until the rewarming phase.

I am interested to know why you continue to use the alpha-stat strategy. We and others, including the group in Philadelphia, have demonstrated, both in the laboratory and in a prospective, randomized clinical study, that clinical use of the alpha-stat strategy is associated unequivocally with a greater incidence of adverse events. Might you repeat this study using the $\mathrm{pH}$-stat strategy with a higher hematocrit value and higher flows than you have used in this study and compare these results with the results of your present study?

I am delighted that you are undertaking this very important work, and I look forward to the results of your next study.

Dr Pigula. Thank you, Dr Jonas. Certainly the study should be repeated with pH-stat management. As you and others have shown, that does bear important consideration.

I agree entirely with your assessment of the decline in oxygen uptake by the brain as a function of hypothermia, alkalosis, and hemoglobin that may be related to our CPB management. What I do not understand is why we are continuing to have relatively stable uptake in glucose during that time when we would expect, on the basis of aerobic metabolism, that glucose and oxygen should be taken up in amounts relative to their stoichiometric relationship. The findings of continued glucose uptake in the face of decreased oxygen uptake suggest an imbalance in substrate management by the brain. Such an imbalance in basic substrate economy may have important implications.

\section{Targeted}

The Journal of Thoracic and Cardiovascular Surgery gives you two tables of contents.

The condensed table of contents tells you at a glance what topics and authors are presented each month. The expanded table of contents gives you a brief abstract of each article. You select only those articles of most interest to you for further reading. 